\title{
Estudo Comparativo de Diferentes Tipos de Polibutadieno na Tenacificação de Poliestireno
}

\author{
Fernanda M. B. Coutinho, Marcia P. M. Costa \\ Instituto de Química, UERJ \\ Maria José 0. C. Guimarães \\ Escola de Química, UFRJ
}

\section{Bluma G. Soares \\ Instituto de Macromoléculas Professora Eloisa Mano, UFRJ}

\begin{abstract}
Resumo: Neste trabalho foi avaliada a tenacificação de poliestireno (PS) utilizando três tipos de polibutadieno (PB): polibutadieno baixo-cis $\left(\mathrm{PB}_{\mathrm{b}}\right)$, polibutadieno alto-cis $\left(\mathrm{PB}_{\mathrm{a}}\right)$ e copolímero em bloco (SBS) de estireno e butadieno $\left(\mathrm{PB}_{\mathrm{co}}\right)$. Foi observado um aumento na resistência ao impacto de 138, 208 e 823\%, quando foram utilizados polibutadieno baixo-cis, polibutadieno alto-cis e copolímero em bloco de estireno e butadieno respectivamente. Os materiais apresentaram morfologia dispersa com domínios de polibutadieno distribuídos aleatoriamente na matriz de poliestireno, cujo tamanho foi inferior a $1 \mu \mathrm{m}$. A energia de ativação para o escoamento foi calculada segundo a equação de Arrhenius e variou de $34 \mathrm{a} 71 \mathrm{~kJ} / \mathrm{mol}$. Em todos os experimentos reológicos as misturas poliméricas apresentaram comportamento pseudoplástico.
\end{abstract}

Palavras-chave: Tenacificação, poliestireno, polibutadieno, propriedades.

\section{Comparative Study of Different Types of Polybutadiene on the Toughening of Polystyrene}

Abstract: In this work, an evaluation was made of the toughening of polystyrene (PS) with three types of polybutadiene $(\mathrm{PB})$ : low-cis polybutadiene $\left(\mathrm{PB}_{\mathrm{l}}\right)$, high-cis polybutadiene $\left(\mathrm{PB}_{\mathrm{h}}\right)$ and styrene-butadiene block (SBS) copolymer $\left(\mathrm{PB}_{c 0}\right)$. The impact strength increased 138, 208 and 823\% when low-cis polybutadiene, high-cis polybutadiene and styrene-butadiene block copolymer, were used, respectively. The materials presented dispersed morphology with domains smaller than $1 \mu \mathrm{m}$, randomly distributed in the polystyrene matrix. The flow activation energy, calculated by Arrhenius equation, varied from 34 to $71 \mathrm{~kJ} / \mathrm{mol}$. In the rheological experiments all polymer blends presented pseudoplastic behavior.

Keywords: Toughening, polystyrene, polybutadiene, properties.

\section{Introdução}

Poliestireno (PS) é um polímero termoplástico, facilmente sintetizado, processado e reciclado. É relativamente resistente à degradação, entretanto, possui baixa resistência ao impacto. Para certas aplicações o poliestireno necessita ser tenacificado ${ }^{[1]}$.

A tenacificação é um dos parâmetros mais importantes que determina se um dado polímero pode ser usado como material de engenharia. Nas misturas de termoplásticos reforçados com elastômeros, quando se aplica uma tensão, as partículas elastoméricas dispersas concentram ou absorvem essa tensão, provocando uma alteração do estado de tensão da fase matricial e uma intensa deformação plástica, melhorando assim a resistência ao impacto do material. A absorção-dissipação de energia pelas partículas dispersas ocorre por diferentes mecanismos, tais como, cavitação, deformação plástica e por deformação-cavitação ${ }^{[2-4]}$.
Os fatores que afetam a resistência ao impacto desses materiais são a fração mássica do elastômero, tamanho, distribuição e morfologia das partículas elastoméricas, temperatura de transição vítrea (Tg) e afinidade química ou nível de adesão interfacial entre os polímeros constituintes ${ }^{[5-8]}$. Um agente compatibilizante pode ser adicionado à mistura polimérica a fim de melhorar a adesão interfacial. No caso de copolímeros em bloco, uma boa adesão entre os segmentos dos blocos do copolímero com as fases matricial e dispersa, melhora a transferência de tensão entre essas fases resultando na melhoria das propriedades interfaciais com conseqüente diminuição da separação e do tamanho da fase dispersa ${ }^{[9]}$.

Poliestireno de alto impacto (HIPS) são materiais obtidos a partir da combinação de poliestireno e polibutadieno, utilizando processo de graftização ou mistura no estado fundido. A tenacificação de poliestireno tem sido feita pela incorporação de $20 \%$ de polibutadieno contendo $40 \%$ de unidades $1,4 \mathrm{cis}, 50 \%$ 1,4 trans e 10\% 1,2 vinílicas ${ }^{[10-17]}$.

Autor para correspondência: Fernanda M. B. Coutinho, Departamento de Processos Químicos, Instituto de Química, UERJ, Rua São Francisco Xavier 524, Pavilhão Haroldo Lisboa da Cunha, CEP: 20559-900, Rio de Janeiro, RJ, Brasil. E-mail: fmbc@uerj.br 
O polibutadieno com alto teor de unidades 1,4 cis é o mais nobre dos isômeros e é o único que, na forma pura, se comporta como elastômero à temperatura ambiente. Apresenta excelentes propriedades mecânicas, tais como, resistência à abrasão, resistência à fadiga e resistência ao rasgo, sendo utilizado principalmente na indústria de pneumáticos ${ }^{[18,19]}$.

As misturas poliméricas produzidas com poliestireno e polibutadieno alto-cis ( $\mathrm{PS} / \mathrm{PB}_{\mathrm{a}}$ ) são materiais de importância comercial. Entretanto, a literatura sobre esse tipo de material ainda é limitada ${ }^{[20-22]}$. Assim, neste trabalho, foi feito um estudo comparativo da tenacificação de PS utilizando três tipos de polibutadieno: polibutadieno baixo-cis $\left(\mathrm{PB}_{\mathrm{b}}\right)$, polibutadieno alto-cis ( $\mathrm{PB}_{\mathrm{a}}$ ) e um copolímero em bloco (SBS) de estireno-butadieno $\left(\mathrm{PB}_{\mathrm{co}}\right)$ e suas influências nas propriedades mecânicas, morfológicas e reológicas dos materiais obtidos.

\section{Experimental}

\section{Materiais e processamento}

Os materiais utilizados neste trabalho estão especificados na Tabela 1.

As misturas foram processadas em misturador HAAKE Rheomix 600 , a $180{ }^{\circ} \mathrm{C}, 60$ rpm durante 6 minutos, utilizando percentagem mássica de polibutadieno (PB) de $20 \%$.

\section{Caracterização das misturas}

\section{Morfologia}

A morfologia das misturas poliméricas foi analisada por microscopia eletrônica de varredura (MEV) em equipamento Jeol JSM $6460 \mathrm{LV}$, utilizando corpos de prova obtidos por compressão, fraturados em $\mathrm{N}_{2}$ líquido, extraídos com mistura de heptano/hexano (1:1) e $\mathrm{HCl} 20 \%$. Os corpos de prova após extração foram secos a temperatura ambiente, recobertos com uma fina camada de ouro e analisados sob voltagem de $15 \mathrm{kV}$.

\section{Propriedades Mecânicas}

\section{Ensaio de dureza Shore D}

A determinação da resistênca à penetração ou ao risco foi realizada de acordo com a norma ASTM D2240, em equipamento Shore-Durometer Hardness Type “D”, cuja força aplicada é controlada por mola calibrada por meio de indentores padronizados para o durômetro.

\section{Resistência à tração}

As propriedades tênseis foram medidas em equipamento Emic DL 10000-Universal Mechanical Testing Machine a $23,8{ }^{\circ} \mathrm{C}$ e $58 \%$ de umidade relativa. Os corpos de prova medindo $100 \mathrm{~mm}$ de comprimento $x$ 5,20 mm de largura $x$ 2,30 mm de espessura, obtidos por compressão, foram ensaiados segundo a norma ASTM 638-II. As análises foram conduzidas sob velocidade de estiramento de $3 \mathrm{~mm} / \mathrm{min}$ e uma média de dez corpos de prova foram utilizados para cada composição.

\section{Resistência ao impacto}

Os ensaios de resistência ao impacto foram realizados em equipamento Resil Impactor Ceast SPA Impactor Tester no modo Izod com entalhe segundo a norma ASTM D256. Os corpos de prova, de dimensões $12 \times 6 \times 3 \mathrm{~mm}$, foram obtidos por compressão em uma Prensa Carver a $180{ }^{\circ} \mathrm{C}$ e $68 \mathrm{MPa}$ durante um período de 5 minutos e resfriados em prensa hidráulica com circulação de água por 3 minutos sob a mesma pressão. Foram analisados nove corpos de prova para cada mistura.

\section{Análise reológica}

As propriedades viscoelásticas foram avaliadas em reômetro dinâmico da Anton Paar Physica MCR 301 com geometria de placas paralelas nas temperaturas de 190, 200 e $210{ }^{\circ} \mathrm{C}$. A viscosidade complexa $\left(\eta^{*}\right)$, o módulo de armazenamento $\left(G^{\prime}\right)$ e o módulo de perda (G”) foram determinados em uma faixa de freqüência angular de $10^{-1}$ a $10^{2} \mathrm{rad} / \mathrm{s}$ sob atmosfera de $\mathrm{N}_{2}$. Todas as amostras foram avaliadas na faixa de viscoelasticidade linear.

\section{Resultados e Discussão}

\section{Processamento das misturas}

As condições de processamento tiveram influência marcante na qualidade dos materiais obtidos. Foi observado que temperaturas de processamento maiores que $180^{\circ} \mathrm{C}$ acarretam a degradação do material. A incorporação de material elastomérico à matriz do PS produz materiais opacos. A Figura 1 mostra as curvas típicas de processamento das misturas poliméricas produzidas com diferentes tipos de polibutadieno.

Observa-se que o poliestireno apresenta um torque maior no estágio inicial do processamento, do que as misturas PS/ PB. Esse comportamento deve-se ao fato do o ao poliesti-

Tabela 1. Especificações dos polímeros.

\begin{tabular}{|c|c|c|c|c|}
\hline Especificação & Poliestireno (PS) & Polibutadieno baixo-cis $\left(\mathrm{PB}_{\mathrm{b}}\right)$ & Polibutadieno alto-cis $\left(\mathrm{PB}_{\mathrm{a}}\right)$ & 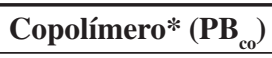 \\
\hline Fornecedor & EDN & Petroflex & Petroflex & Petroflex \\
\hline $\operatorname{Tg}\left({ }^{\circ} \mathrm{C}\right)$ & 100 & -92 & -110 & -98 \\
\hline Densidade $\left(\mathrm{g} / \mathrm{cm}^{3}\right)$ & 1,05 & 0,89 & 1,00 & 0,4 \\
\hline MFI (g/10 min) & 3 & - & - & 7,7 \\
\hline Viscosidade Mooney & - & 47,0 & 42,0 & - \\
\hline Teor de unidades 1,4 cis & - & 36 & 97 & - \\
\hline
\end{tabular}

*Copolímero em bloco de estireno-butadieno $(\mathrm{m} / \mathrm{m}=31 / 69)$. 


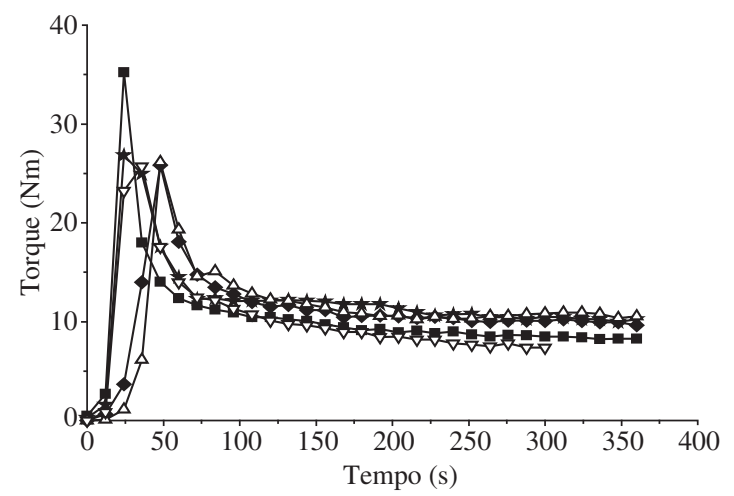

Figura 1. Curvas de torque versus tempo: $\mathrm{PS}(\bullet)$; $\mathrm{PS}_{\mathrm{PB}}(\star)$; $\mathrm{PS} / \mathrm{PB}_{\mathrm{a}}(\bullet)$; $\mathrm{PS} / \mathrm{PB} / \mathrm{PB}_{\mathrm{co}}(\triangle) ; \mathrm{PS}_{\mathrm{PB}}(\nabla)$.

reno, no estágio inicial, não estar ainda totalmente fundido. $\mathrm{Na}$ presença de um material flexível como o polibutadieno, a mistura se torna mais fácil de ser processada, como pode ser visto na Figura 1. A partir de 120 segundos não ocorre mais variação de torque, indicando que os materiais estão totalmente fundidos e homogêneos.

\section{Análise morfológica}

A morfologia gerada em um processo de mistura pode ser do tipo dispersa, estratificada ou co-contínua. O tipo específico de morfologia obtida está diretamente relacionada às condições de processamento, composição e, principalmente,
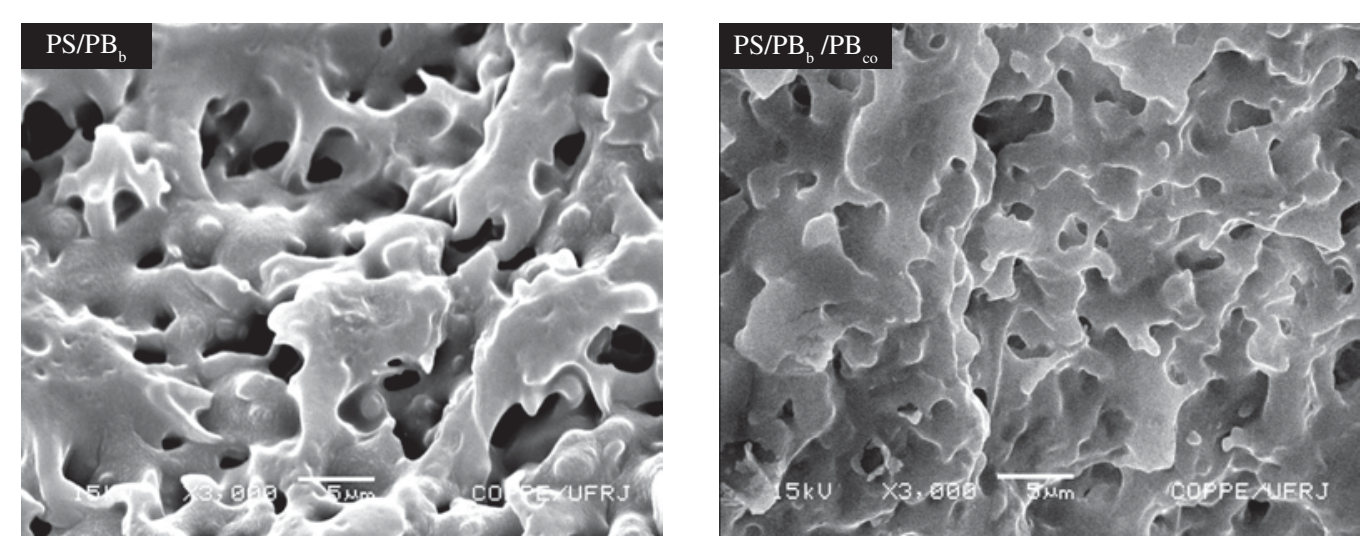

(a)
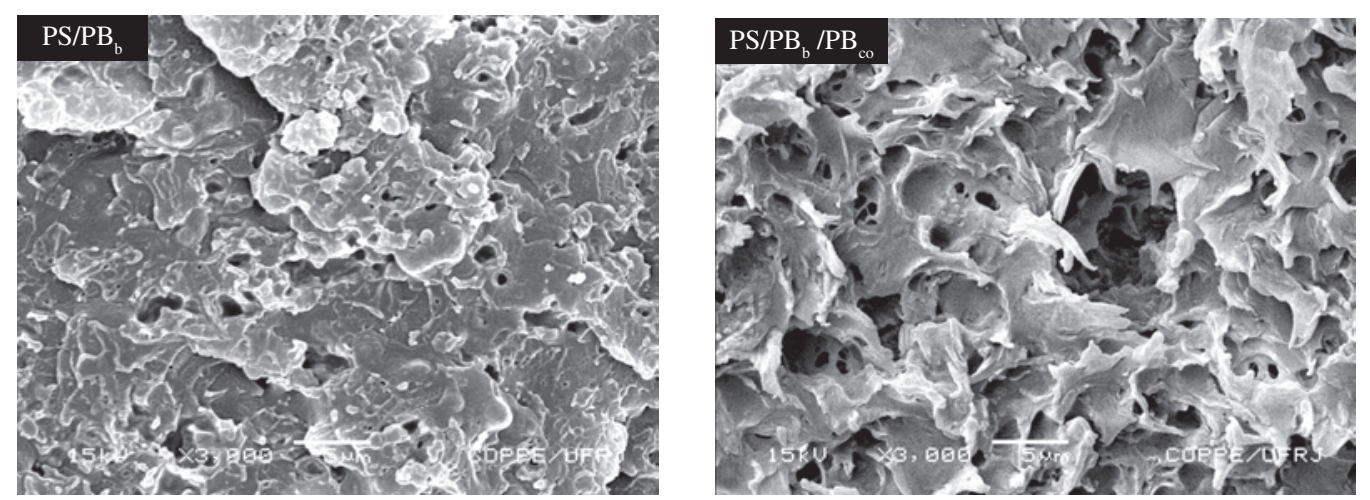

(b)

Figura 2. Micrografias de SEM de PS/PB: a) extração feita com heptano/hexano; e b) extração feita com HCl.
${ }^{*} \mathrm{~PB}_{\mathrm{co}}-$ agente compatibilizante $(2,5 \%)$.

\begin{tabular}{llc}
\hline Material & Solvente & Diâmetro $(\mu \mathbf{m})$ \\
\hline $\mathrm{PS} / \mathrm{PB}_{\mathrm{b}}$ & & $0,62 \pm 0,3$ \\
$\mathrm{PS} / \mathrm{PB}_{\mathrm{a}}$ & Heptane/hexane $(1: 1)$ & $0,63 \pm 0,3$ \\
$\mathrm{PS} / \mathrm{PB}_{\mathrm{b}} / \mathrm{PB}_{\mathrm{co}}{ }^{*}$ & & $0,50 \pm 0,2$ \\
$\mathrm{PS} / \mathrm{PB}_{\mathrm{a}} / \mathrm{PB}_{\mathrm{co}}{ }^{*}$ & & $0,54 \pm 0,2$ \\
\hline $\mathrm{PS} / \mathrm{PB}_{\mathrm{b}}$ & $\mathrm{HCl} \mathrm{20 \%}$ & $0,24 \pm 0,2$ \\
$\mathrm{PS} / \mathrm{PB}_{\mathrm{a}}$ & & $0,41 \pm 0,2$ \\
$\mathrm{PS} / \mathrm{PB}_{\mathrm{b}} / \mathrm{PB}_{\mathrm{co}}{ }^{*}$ & & $0,34 \pm 0,2$ \\
$\mathrm{PS} / \mathrm{PB}_{\mathrm{a}} / \mathrm{PB}_{\mathrm{co}}{ }^{*}$ & & $0,40 \pm 0,2$ \\
\hline
\end{tabular}

às propriedades reológicas dos componentes da mistura. A estabilidade morfológica é função da tensão interfacial entre as fases e da termodinâmica do sistema.

As misturas produzidas com diferentes tipos de polibutadieno apresentaram morfologia bifásica com domínios elastoméricos de tamanhos inferiores a $1 \mu \mathrm{m}$, dispersos aleatoriana matriz de poliestireno (Tabela 2 ). com polibutadieno baixo-cis ( $\left.\mathrm{PB}_{\mathrm{b}}\right)$, polibutadieno alto$\left(\mathrm{PB}_{\mathrm{a}}\right)$ e usando $2,5 \%$ de copolímero em bloco de estirenobutadieno $\left(\mathrm{PB}_{\mathrm{co}}\right)$ como agente compatibilizante.

$\mathrm{O}$ agente de extração teve uma influência significante nos tamanhos dos domínios elastoméricos. Os domínios elasto-

Tabela 2. Diâmetro médio das partículas. 

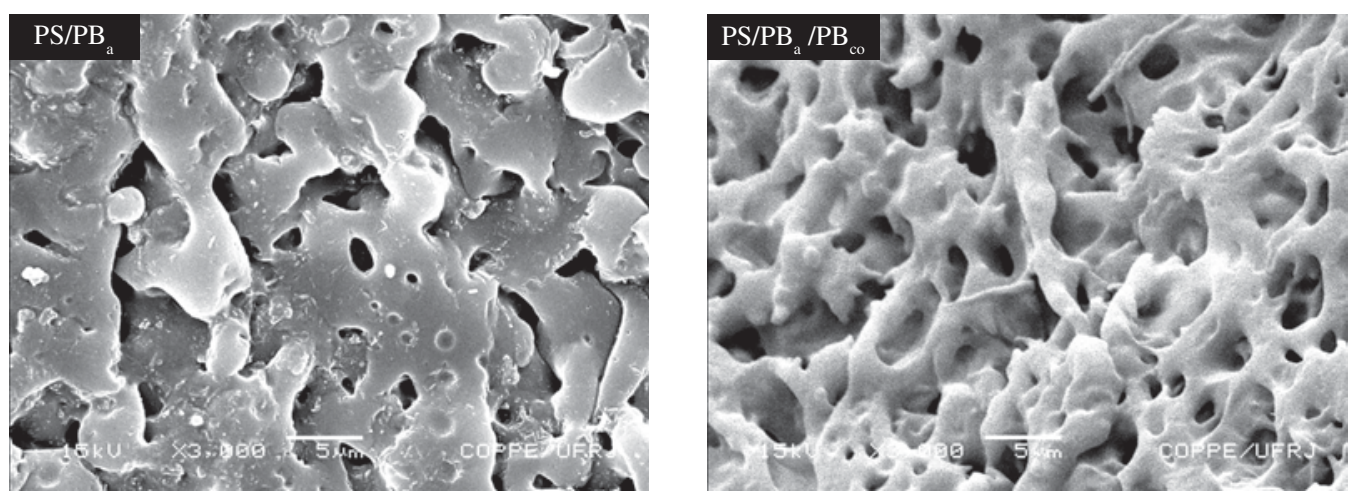

(a)
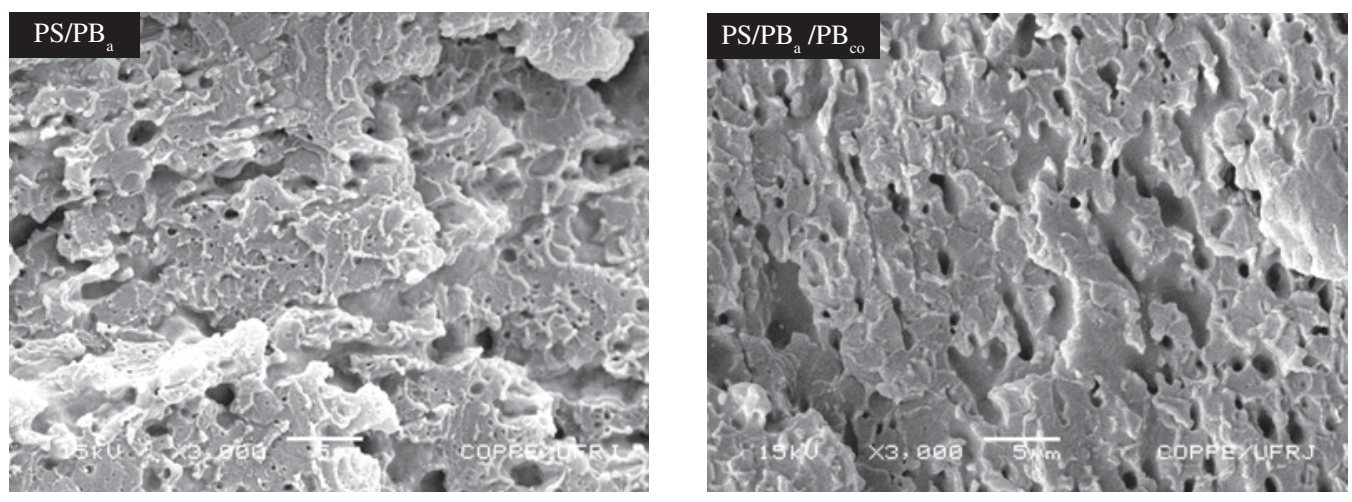

(b)

Figura 3. Micrografias de SEM de PS/PB

méricos foram maiores em todas as misturas em que o agente de extração utilizado foi o heptano/hexano do que quando o $\mathrm{HCl}$ foi usado. Esse fato pode ser atribuído a um certo grau de inchamento da matriz de poliestireno no solvente orgânico.

A adição do agente compatibilizante $\left(\mathrm{PB}_{\mathrm{co}}\right)$ influenciou o tamanho das partículas devido ao aumento da adesão interfacial entre as fases.

\section{Propriedades mecânicas}

O comportamento mecânico de materiais poliméricos é baseado nas deformações causadas pela aplicação de forças externas. A natureza dessas forças varia conforme o tipo de tensão ao qual o material está sendo submetido e a aplicação final é governada principalmente por suas propriedades mecânicas. Essas propriedades, por sua vez, são dependentes do nível de homogeneidade, compatibilidade e da adesão interfacial entre os constituintes do sistema ${ }^{[23,24]}$.

\section{Dureza Shore D}

A determinação da dureza é baseada na medida da impressão feita por um indentor no material sob uma carga constante. A Figura 4 apresenta os valores de dureza das várias misturas.

As misturas poliméricas apresentaram valores de dureza mais baixos em relação ao PS puro. Esse comportamento deve-se à incorporação do elastômero na matriz de poliestireno. Os valores de dureza obtidos para as misturas PS/PB estão próximos ao valor de dureza do HIPS comercial preparado por graftização o qual é 52 Shore D.

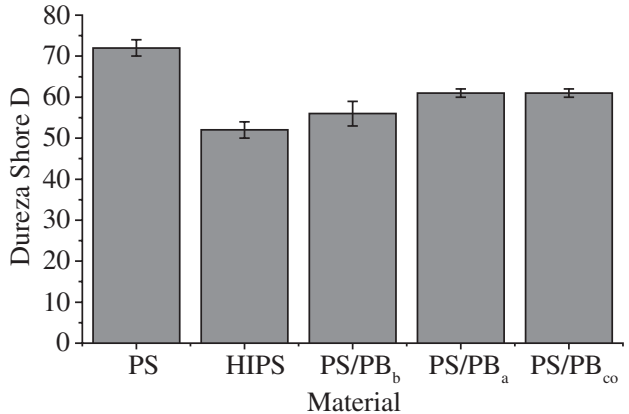

Figura 4. Valores comparativos do ensaio de dureza das misturas (PS/PB).

\section{Ensaios mecânicos}

A Tabela 3 apresenta os resultados dos ensaios mecânicos das misturas PS/PB e na Figura 5a-c), esses resultados são apresentados graficamente.

Os resultados mostraram que o módulo de Young e a tensão de ruptura, para todas as misturas, decresceram em relação ao poliestireno. O alongamento não foi afetado quando $\mathrm{PB}_{\mathrm{b}}$ ou $\mathrm{PB}_{\mathrm{a}}$ foram incorporados na matriz de PS. No entanto, quando foi incorporado o copolímero em bloco de estirenobutadieno $(20 \%)$ observou-se um aumento significativo no alongamento $(\varepsilon=43 \%)$. Quando o copolímero em bloco foi adicionado à matriz de poliestireno como agente compatibilizante $(2,5 \%)$ o alongamento na ruptura foi de apenas $3 \%$.

A Figura 6 apresenta as curvas típicas de comportamento tênsil do polímero puro (PS) e das misturas com polibutadieno alto e baixo-cis e com o copolímero estireno-butadieno. 
Tabela 3. Resultados dos ensaios mecânicos.

\begin{tabular}{cccccc}
\hline & $\mathbf{P S}$ & $\mathbf{P S} / \mathbf{P B}_{\mathbf{b}}$ & $\mathbf{P S} / \mathbf{P B}_{\mathbf{a}}$ & ${\mathbf{P S} / \mathbf{P B}_{\mathbf{a}} / \mathbf{P B}_{\mathbf{c o}}}_{\mathbf{P S}_{\mathbf{P}}}$ & $\mathbf{P B}_{\mathrm{co}}$ \\
\hline Tensão de Ruptura (MPa) & $31 \pm 3$ & $13 \pm 2$ & $11 \pm 4$ & $12 \pm 2$ & $12 \pm 3$ \\
Módulo de Young (MPa) & $1111 \pm 72$ & $763 \pm 153$ & $787 \pm 138$ & $723 \pm 178$ & $143 \pm 39$ \\
Elongação (\%) & $6 \pm 0,2$ & $22 \pm 6$ & $5 \pm 1$ & $5 \pm 1$ & $128 \pm 37$ \\
\hline
\end{tabular}

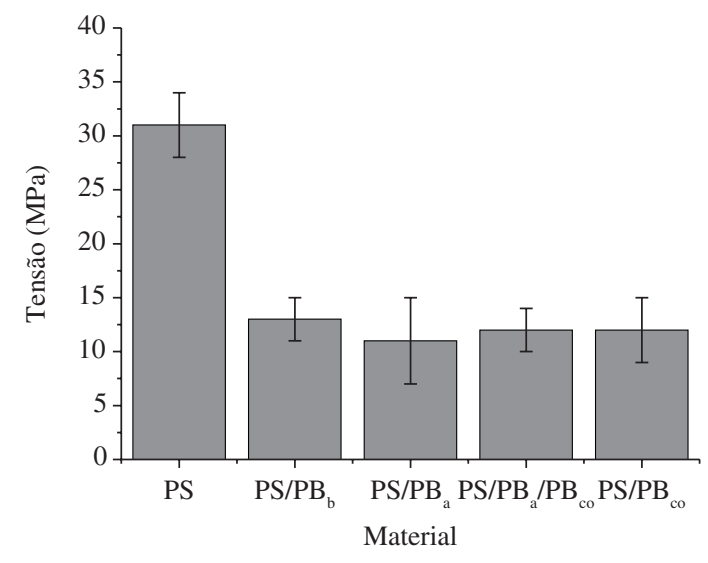

(a)

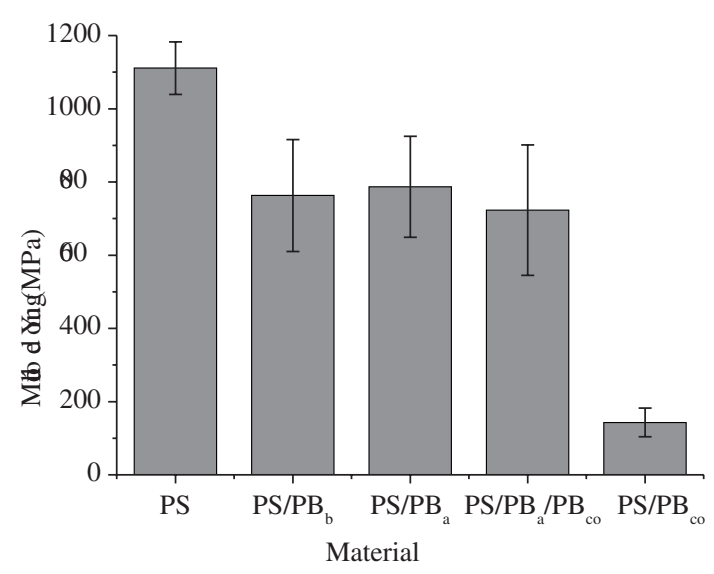

(b)

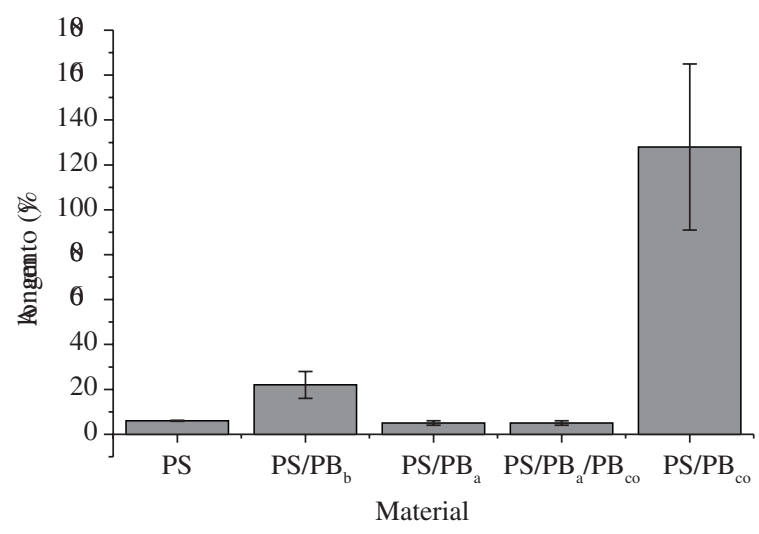

(c)

Figura 5. Ensaios Mecânicos: a) tensão; b) Módulo de Young; e c) alongamento.

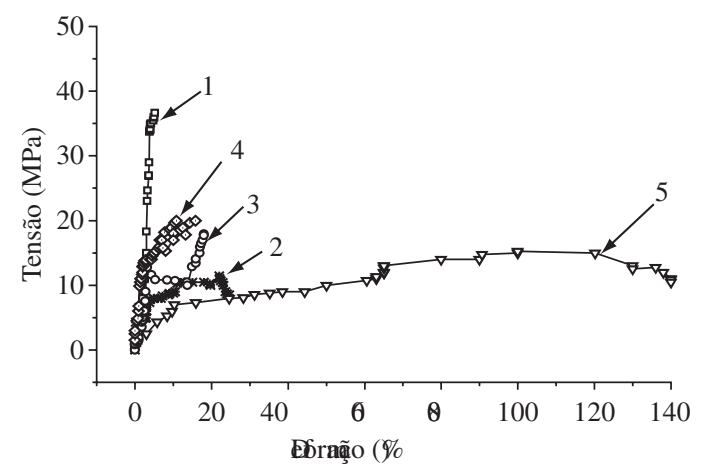

Figura 6. Perfil das curvas de tensão vs. deformação: (1) PS; (2) PS/PB; (3) PS/PB.

O poliestireno puro, como era de se esperar, exibiu comportamento de material duro e quebradiço, sem ponto de escoamento, enquanto que as misturas poliméricas (PS/PB) apresentaram resistência à tração mais baixa e uma pequena flexibilidade antes da ruptura. No entanto, a incorporação do copolímero estireno-butadieno na matriz do PS, provocou uma modificação no comportamento mecânico de quebradiço para tenaz.

Nos ensaios de tração, todas as misturas tornaram-se esbranquiçadas na região de estiramento. O fenômeno de esbranquecimento sob tensão (stress whitening) desses materiais, durante o processo de deformação, é geralmente a manifestação de um processo de cavitação em escala fina. Isso sugere que tanto o PS quanto o PB podem cavitar, produzindo microcavidades com conseqüiente modificação do índice de refração do material durante a deformação plástica, nas condições de teste utilizadas ${ }^{[25]}$.

\section{Resistência ao Impacto}

A Figura 7 apresenta os resultados de resistência ao impacto das misturas PS/PB. A resistência ao impacto de PS

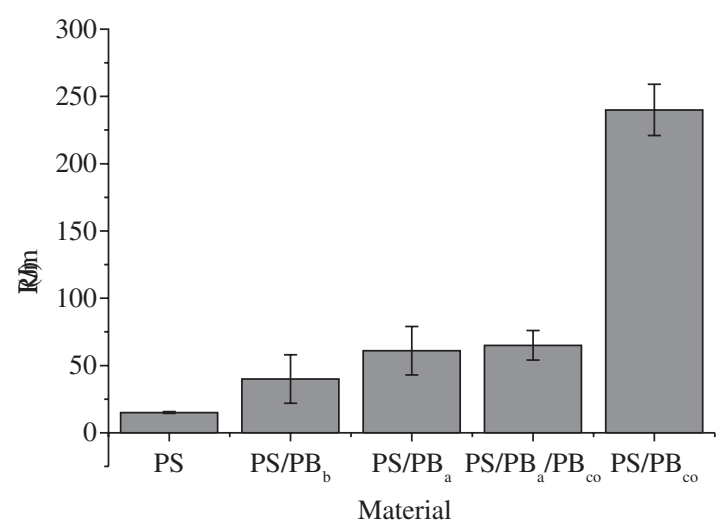

Figura 7. Resistência ao impacto do PS e das misturas (PS/PB). 
tenacificado com polibutadieno alto-cis é maior do que a do PS produzido com polibutadieno baixo cis.

A resistência ao impacto teve um aumento de 138, 208 e $823 \%$ quando foram utilizados respectivamente $\mathrm{PB}_{\mathrm{b}}, \mathrm{PB}_{\mathrm{a}} \mathrm{e}$ $\mathrm{PB}_{\mathrm{co}}$. A elevada resistência ao impacto exibida pela mistura com o PB co é devido ao aumento da adesão entre as fases termoplástica e elastomérica e à diminuição da tensão interfacial, conferindo ao material uma morfologia mais estável. Todas as amostras apresentaram também o fenômeno de esbranquecimento sob tensão na região de ruptura.

\section{Propriedades reológicas}

É de essencial importância se conhecer o comportamento viscoelástico de misturas poliméricas, não apenas como forma de se alcançar condições otimizadas de processamento, mas também, para se obter valiosas informações sobre o tipo de escoamento e seu efeito sobre a morfologia e as propriedades mecânicas finais. A viscosidade, propriedade reológica fundamental de um fluido, é afetada pelas condições de processamento (taxa de cisalhamento, temperatura e pressão) e pelo tipo de material utilizado (estrutura química, peso molecular e polidispersão, presença de ramificações de cadeia curta e longa) e pela presença de cargas e aditivos ${ }^{[26,27]}$.

A Figura 8a-c apresenta as análises reológicas de misturas físicas de poliestireno com os três tipos de polibutadieno.

Todas as amostras apresentaram comportamento pseudoplástico e viscoelasticidade em toda a faixa de freqüência estudada. Os PB's apresentaram os maiores valores de viscosidade $(\eta)$, enquanto o PS apresentou os menores valores.

As misturas físicas de poliestireno com os três tipos de polibutadieno apresentaram comportamento viscoelástico, com os módulos elástico $\left(\mathrm{G}^{`}\right)$ e de perda ( $\mathrm{G}^{\text {‘)}}$ ) aumentando com o aumento da freqüência aplicada. As curvas reológicas das misturas, ficaram entre as curvas dos componentes puros.

A Figura 9 mostra os valores da energia de ativação para os polímeros puros e suas misturas. A energia de ativação das misturas poliméricas, calculada pela equação de Arrhenius, variou de 34 a $71 \mathrm{~kJ} / \mathrm{mol}$.

A energia de ativação para as misturas é menor do que para o PS puro. Os valores de energia de ativação para PS/ $\mathrm{PB}_{\mathrm{b}}$ e PS/PB ${ }_{\text {co }}$ são os mesmos, entretanto esse valor dobra quando é utilizado $\mathrm{PB}_{\mathrm{a}}$ como modificador.

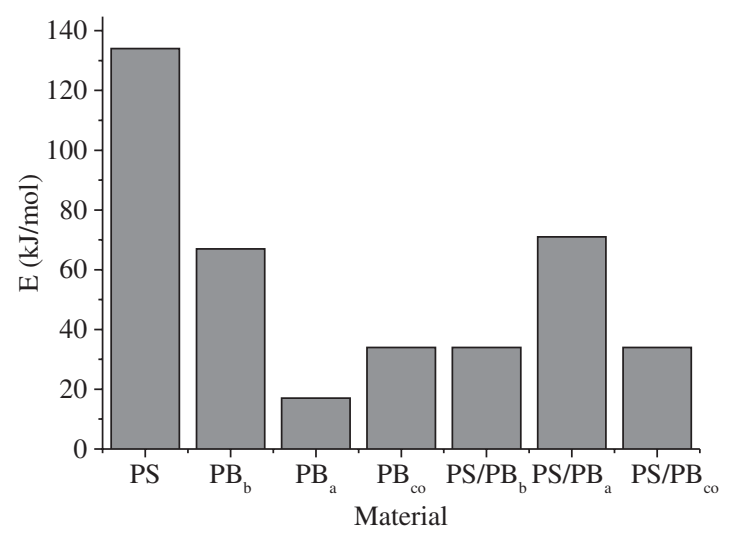

Figura 9. Energia de ativação das misturas PS/PB.

\section{Conclusões}

As condições de processamento tiveram influência marcante na qualidade dos materiais obtidos. Temperaturas de processamento superiores à $180{ }^{\circ} \mathrm{C}$ provocam a degradação do material. As misturas PS/PB exibiram morfologia bifásica com domínios de polibutadieno dispersos aleatoriamente na matriz do PS, com diâmetro de partícula inferior a $1 \mu \mathrm{m}$. Essas misturas apresentaram baixa adesão entre as fases termoplástica e elastomérica e uma alta tensão interfacial. A incorporação de material elastomérico à matriz do PS produziu materiais opacos com alta resistência ao impacto. As misturas $\mathrm{PS} / \mathrm{PB}_{\mathrm{a}}$ apresentaram valores de resistência ao impacto superiores aos das misturas $\mathrm{PS} / \mathrm{PB}_{\mathrm{b}}$ e muito inferiores aos das misturas $\mathrm{PS} / \mathrm{PB}_{\text {co }}$. Todos os materiais produzidos neste estudo tiveram resistência ao impacto superior a do HIPS comercial.

Todas as misturas poliméricas estudadas neste trabalho apresentaram comportamento pseudoplástico e viscoelasticidade e diferentes energia de ativação para o escoamento sob as condições de cisalhamento estudadas.

\section{Agradecimentos}

À FAPERJ e ao CNPq pelo apoio financeiro e à Petroflex e EDN pela doação dos materiais.

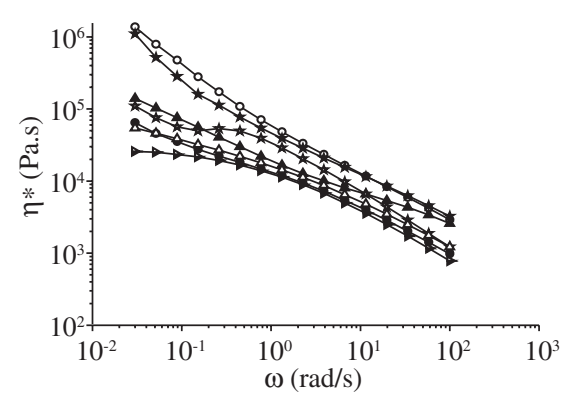

(a)

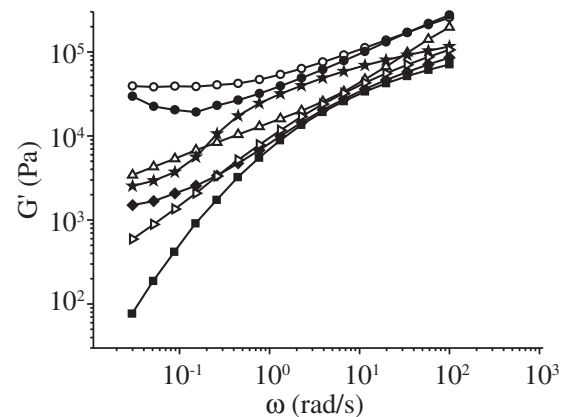

(b)

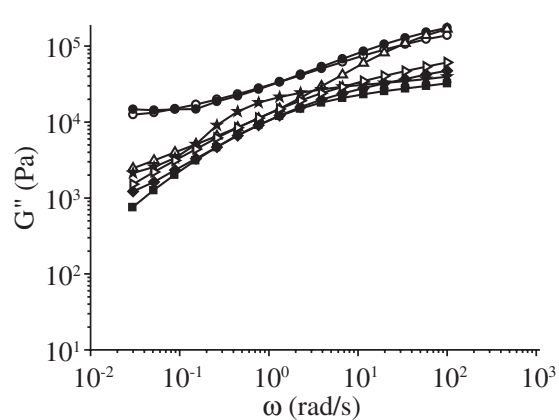

(c)

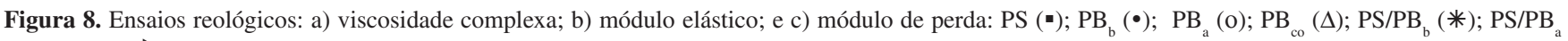
$(\bullet) ; \mathrm{PS} / \mathrm{PB}_{\mathrm{co}}(\triangleright)$. 


\section{Referências Bibliográficas}

1. Baltá-Calleja, F. J.; Cagio, M. E.; Adhikari, R. \& Michler, G.H. - Polymer, 45, p.247 (2004).

2. Lotti, C.; Correa, C. A. \& Canevarolo, S. V. - Mat. Res., 3 p.37 (2000).

3. Jiang W.; An, L. \& Jiang, B. - Polymer, 42, p.4777 (2001).

4. Lung, H.; Jiang, W.; Zhang J. \& Jiang, B. - J. Appl. Polym. Sci., 59, p.505 (1996).

5. Cavanaugh, T. J.; Buttle, K.; Turner,J. N. \& Nauman E. B. - Polymer, 39, 18, p.4191 (1998).

6. Dagli, G.; Argon, A. S. \& Cohen, E. R. - Polymer, 36, 11, p.2173 (1995).

7. Sundararaj, U.; Macosko, C. W.; Roland, R. J. \& Chan, H. T. - Polym. Eng. Sci., 32, 24, p.1814 (1992).

8. Joseph, S. \& Thomas, S. - Eur. Polym. J., 39, p.115 (2003).

9. Silberg, J. \& Han C. D. - J. Appl.Polym. Sci., 22, p.599 (1978).

10. Cook, D. G.; Rudin, A. \& Plumtree, A. - Plast. Rub. and Comp. Proc. Appl., 20, 4, p.219 (1993).

11. Fayt, R.; Hadjiandreous, P. \& Teyssie, P. - J. Polym. Sci., 23, 2, p. 337 (1985).

12. Piorkowska, E.; Argon, A. S. \& Cohen, E. R. - Polymer, 34, 21, p.4435 (1993).

13. Peng, M. F. - J. Appl. Polym. Sci., 40, 7, p.1289 (1990).

14. Fisher, M. \& Hellmann, G. P. - Macromolecules, 29, p.2498 (1996).
15. Maestrini, C.; Monti, L. \& Kausch, H. H. - Polymer, 37, 9, p.1607 (1996).

16. Maestrini, C.; Pisoni, K. \& Kausch, H. H. - J. Mat. Sci., 31, 12, p.3249 (1996)

17. Alfarraj, A. \& Nauman, E. B. - Polymer, 45, p.8435 (2004).

18. Pires, N. M. T.; Coutinho, F. M. B.; Costa, M. A. S.; Santa Maria, L. C.; Mello, I. L. \& Nunes, D. S. S. - Revista de Química Industrial, 719 (2002).

19. Pires, N. M. T.; Coutinho, F. M. B. \& Costa, M. A. S. Eur. Polym. J., 40, p.2599 (2004).

20. Mui,C. T. E.; Boating, B. V.; Fellers, F. J. \& White L. J. - J. Appl. Polym. Sci., 27, p.1395 (1982).

21. Joseph, S.; Lauprête, F.; Negrell, C. \& Thomas, S. - Polymer, 46, p.9385 (2005).

22. Joseph, S.; Oommen, Z. \& Thomas, S. - Mat. Let., 53, p.268 (2002).

23. LA Mantia, F. P. \& Acierno, D. - Eur. Polym. J., 21, p.811 (1985).

24. Barlow, J. W. \& Paul, D. R. - Polym. Eng. Sci. 21, p.985 (1981).

25. Magalhães, A. M. L. \& Borggreve, R. J. M. - Macromolecules, 28, p.5841 (1995)

26. Bretas, R. E. S. \& D’Avila, M. A. - "Reologia de Polímeros fundidos", Editora UFScar, (2000).

27. Rohn, C. L. - Analytical Polymer Rheology: StructureProcessing-Properties Relationships, Hans Publishers, NY, 1995

Enviado: $14 / 02$

Reenviado: $10 / 09 / 07$

Aceito: $17 / 09 / 07$ 